\title{
Emulsion liquid membrane extraction of polyphenols compound from palm oil mill effluent
}

\author{
Norela Jusoh a, Norasikin Othman a, b, ${ }^{*}$, Gabriella Geeta ${ }^{a}$, Muhammad Bukhari Rosly a, Raja \\ Norimie Raja Sulaiman ${ }^{a}$, Norul Fatiha Mohamed Noah ${ }^{\text {a }}$, Khairul Sozana Nor Kamarudin a
}

a School of Chemical and Energy Engineering, Universiti Teknologi Malaysia, 81310 UTM Johor Bahru, Johor, Malaysia

${ }^{b}$ Centre of Lipids Engineering and Applied Research, Ibnu Sina Institute for Scientific and Industrial Research Universiti Teknologi Malaysia, 81310 UTM Johor Bahru, Johor, Malaysia

* Corresponding author: norasikin@cheme.utm.my

\section{Article history}

Received 20 February 2019

Revised 18 March 2019

Accepted 2 May 2019

Published Online 2 February 2020

\section{Graphical abstract}

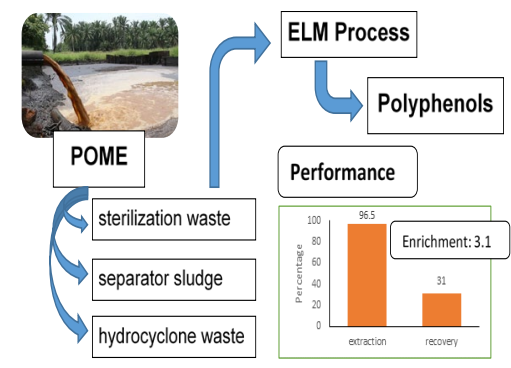

\begin{abstract}
Polyphenols possess many health attributes, as they are powerful antioxidants. Recovery of valueadded compounds from industrial waste is a new approach in order to promote sustainability. In this study, the extraction of polyphenols from palm oil mill sterilization condensate by emulsion liquid membrane (ELM) process is proposed. The sterilization condensate was first characterized to determine the total phenolic content (TPC) in the sample. For the extraction, liquid membrane was formulated to choose the best diluent, carrier, and stripping agent. Once the formulation was successfully attempted, the extraction of polyphenols to recover polyphenols was performed. The results show that $2627.3 \mathrm{mg} \mathrm{GAE} / \mathrm{L}$ of TPC was obtained in the condensate. During the liquid membrane formulation, palm oil was chosen as a green diluent, TBP and n-Octanol were selected as the most appropriate carriers for synergize in a composition of 8:2 by volume, while sodium hydroxide was selected as the most appropriate stripping agents to best facilitate the extraction process. The extraction and recovery performance of polyphenols showed performance of $96.5 \%$ and $31 \%$, respectively. The findings of this study show that ELM is a potential technology to extract and recover polyphenols from palm oil mill sterilization condensate.
\end{abstract}

Keywords: Polyphenols, extraction, emulsion liquid membrane, palm oil mill effluent, sterilization condensate

\section{INTRODUCTION}

Malaysia is renowned as the largest manufacturer and exporter of palm oil. Palm oil processing in Malaysia is executed in palm oil mills where oil is extracted from a palm oil fruit bunch. In this process, large amounts of water are used for the extraction of crude palm oil from the fresh palm oil fruit bunch and about $50 \%$ of the water ends up in palm oil mill effluent (POME). POME consists of thick brownish liquid that contains elevated amounts of total solids $(40,500 \mathrm{mg} / \mathrm{L}), \mathrm{COD}(50,000$ $\mathrm{mg} / \mathrm{L})$ and $\operatorname{BOD}(25,000 \mathrm{mg} / \mathrm{L})$, and oil and grease $(4000 \mathrm{mg} / \mathrm{L})$ [1]. In a conventional palm oil mill, POME consists of mainly three types of waste, that is, the sterilization waste, separator sludge, and hydrocyclone waste. POME is also regarded as a potent source of natural antioxidants due to its rich content of phenolic compounds. Since sterilization is the first step in palm oil processing that uses steam to soften the fruits and increase oil yield, it is unquestionably one of the critical operations, ensuring the success of subsequent stages. After the operation, the condensate carries oil residue and dissolved organics, which can be considered as a potential source of polyphenols.

Polyphenols are a type of chemical substance that occur naturally in plants. Plant phenolics can be classified as flavonoids or phenolic acid. Flavonoids are some of the most potent free radical scavengers and ion chelators while phenolics act as free radical terminators. Flavonoids are claimed as more powerful than Alpha-tocopherol, Beta- carotene, and vitamin A as anti-oxidants [2-3]. As compared to the benefits of conventional vitamin, antioxidants, and carotenoids, the potential health attributes of dietary polyphenols have only been recognized and acknowledged relatively recent [4-6].

Prior to this, there have been methods used to extract polyphenols from various parts of a plant for their antioxidant properties. These methods including pressurized liquid extraction (PLE), enzyme assisted extraction (EAE), microwave assisted extraction (MAE), pulsed electric field extraction (PEF), ultrasound assisted extraction (UAE), and supercritical fluid extraction (SFE) [7]. When it comes to the wastewater extraction of polyphenols, the method commonly used is the solvent extraction technique [8]. However, the aforementioned methods are known to have certain drawbacks [7,9]. An alternative approach is known as emulsion liquid membrane (ELM) where this extraction technique uses both membrane and solvent extraction method.

The ELM extraction process is one of the potential methods to extract polyphenols. The ELM process have shown substantial potential in the vast application of industrial separations such as in the removal of many chemicals, biomolecules, metal ions, pollutants, and organic compounds [10]. Among other types of liquid membranes, ELM is the most attractive type due to the higher mass transfer area and lower diffusional resistance. ELM processes are of fast extraction and is applicable for extraction of small amounts of solutes. These features 
are the result of high interfacial area for mass transfer in the extraction step and high driving force for the stripping step [11].

Hence, while existing studies suggest extraction of polyphenols from POME, there is none that suggests extraction from the palm oil sterilization steam condensate, which has lower total solids and no mixed effluents unlike that of POME. Therefore, recovery of polyphenols compound from the sterilization steam condensate of palm oil mills is significant for it is a very valuable compound for human health. This study, therefore, aims to develop an extraction process for polyphenols using ELM process. The total phenolic content (TPC) in sterilization condensate was first determined, followed by formulation of emulsion liquid membrane by component screening, and ELM extraction and recovery performance of polyphenols from sterilization condensate.

\section{EXPERIMENTAL}

\section{Materials}

Sterilization condensate was obtained from palm oil mill at Kulai, Johor. Gallic acid (97.5 \% purity), Folin-Ciocalteu reagent, tributylphosphate (TBP, $99 \%$ purity), n-Octanol (99\% purity), Trioctylphosphine oxide (TOPO), kerosene ( $78 \%$ purity), and sorbitan monooleate (Span 80, $\geq 60 \%$ oleic acid) were purchased from Sigma Aldrich. Sodium carbonate $\left(\mathrm{Na}_{2} \mathrm{CO}_{3}, 99 \%\right.$ purity) and dodecane $(99 \%$ purity) were procured from Merck. Sodium hydroxide $(\mathrm{NaOH}, 98 \%$ purity) and palm oil were supplied from J.T. Baker and Lam Soon Edible Oils. All of these materials were of analytical grade and used directly as received without further purification.

\section{Characterization of palm oil mill sterilization condensate}

For characterization, pretreatment via centrifugation of feed solution (100 mL condensate diluted in $100 \mathrm{~mL}$ distilled water) was carried out. The clear supernatant formed from 5 to 8 minutes of centrifugation at $4000 \mathrm{rpm}$ was separated by a separating funnel to obtain aqueous solution. This solution was re-centrifuged under the same conditions and the clear supernatant formed was separated using separating funnel. The collected liquid from the separating process was then diluted 5 times and filtered via vacuum filtration and stored at -18 \#. The supernatants obtained from pretreatment, separation, and filtration methods were used in the determination of total phenolic content (TPC) in the palm oil sterilization condensate by using the Folin-Ciocalteu method and UV-Visible spectrophotometer to detect the TPC. $\mathrm{pH}$ of the solutions was determined using a $\mathrm{pH}$ meter (Mettler Toledo model FE20).

\section{Liquid membrane component selection}

The formulation was initiated with the screening of liquid membrane components, which consists of diluent and carriers using solvent extraction method. Firstly, diluent screening was attempted by mixing $10 \mathrm{~mL}$ of organic solution (1 M carrier in diluent) with an equal volume of palm oil sterilization steam condensate $(10 \mathrm{~mL})$. The diluents used were green diluent (palm oil), conventional kerosene, and dodecane, a hydrocarbon. The solution was shaken using a mechanical shaker at $320 \mathrm{rpm}$ for 18 hours. The duration provided for the extraction process is sufficient for the phases to reach equilibrium [12]. Once the solution settles to equilibrium phases, it was separated using a separating funnel for 15 minutes. Next, the aqueous residue was separated carefully. Then, the concentration of polyphenols extracted by carrier was analyzed with UV-Visible spectrophotometer.

Next, a similar procedure was carried out for carrier screening. An equal volume $(10 \mathrm{~mL})$ of palm oil steam condensate was mixed with 10 $\mathrm{mL}$ of organic solution which encompasses of the chosen diluent and carriers which are the neutral n-Octanol, solvating TBP, and TOPO in three $50 \mathrm{~mL}$ conical flasks, respectively. Next, in order to obtain higher carrier transfer rate, the effect of two synergized carriers was attempted with the synergized carrier of TBP and TOPO, TBP and n-Octanol, followed by n-Octanol and TOPO. The highest synergized carriers will then be used for studying the extraction performance by varying compositions.

Once the most suitable carrier was determined, it was used for screening stripping agents such as basic sodium bicarbonate $\left(\mathrm{Na}_{2} \mathrm{CO}_{3}\right)$ and sodium hydroxide $(\mathrm{NaOH})$. This method is also known as back extraction. The organic residue separated from extraction process was used in reaction with equal amounts $(10 \mathrm{~mL})$ of $\mathrm{Na}_{2} \mathrm{CO}_{3}$ and $\mathrm{NaOH}$ in separate flasks. The following equations were used to calculate the percentage of extraction and stripping:

$$
\begin{aligned}
& \text { Extraction }(\%)=\left(C_{i-} C_{f}\right) / C_{i} \times 100 \\
& \text { Stripping }(\%)=C_{\text {stripped }} /\left(C_{i}-C_{f}\right) \times 100
\end{aligned}
$$

where $C_{i}$ is the initial concentration of polyphenols in the feed phase before extraction, $\mathrm{C}_{\mathrm{f}}$ is the final concentration of polyphenols in the feed phase after extraction process, and $\mathrm{C}_{\text {stripped }}$ is the concentration of polyphenols in the aqueous stripping phase from back extraction. The overall liquid membrane component screening is as shown in Fig. 1.

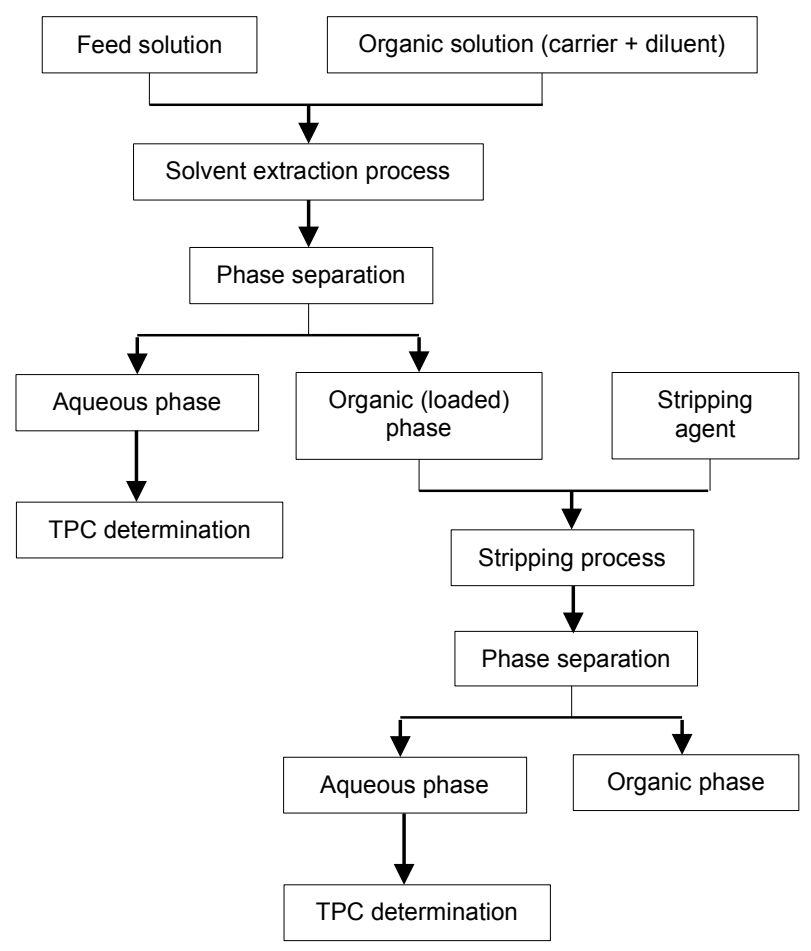

Fig. 1 Flow chart of liquid membrane component selection.

\section{ELM extraction and recovery}

Based on results obtained from the LM formulation and parameter study of carrier concentration and stripping agent concentration, the chosen favorable condition was adopted to study the ELM extraction of polyphenols compound.

The LM (synergized carrier in palm oil and Span 80 as a surfactant) was homogenized with the stripping agent, $\mathrm{NaOH}$ using a motor-driven homogenizer (Heidolph Silent Crusher M, $12000 \mathrm{rpm}, 5$ minutes) to form primary emulsion. The stripping agents and carriers used in this study have a concentration of $1 \mathrm{M}$. The extraction process was initiated by dispersing the primary emulsion in the external feed phase of sterilization condensate. The extraction process was conducted for 3 minutes with a treat ratio of 1:5. After the dispersion, the solution was allowed to settle in a separation funnel. The external phase at the bottom of the funnel was collected for TPC determination using the calorimetric Folin-Ciocalteu method. For recovery purpose, emulsion at the top of the separation funnel were demulsified by ultrasonic vibration (LIR Biotech 020S) at a frequency of $40 \mathrm{kHz}$ for 10 minutes. The internal phase separated from the emulsion phase were collected for TPC determination. To evaluate the ELM performance, Equation 2.1 was used for extraction, while the percentage of recovery and enrichment were determined using Equation 2.3 and 2.4, respectively.

$$
\text { Recovery }(\%)=C_{\text {internal }}\left(C_{i} \times 2 \times T R\right) \times 100
$$

Enrichment $=C_{\text {internal }} / C_{i}$ 
where $C_{i}$ is the initial concentration of polyphenols in the feed phase before extraction and $\mathrm{C}_{\text {internal }}$ is the concentration of polyphenols in the internal phase.

\section{Analytical procedure}

To obtain TPC, the Folin-Ciocalteu phenol reagent technique with Gallic acid as the standard reference phenolic compound was used. A UV-Vis Spectrophotometer (Jenway 7305) at $760 \mathrm{~nm}$ was utilized to measure the absorbance of the samples and was converted into TPC using a Gallic acid calibration curve. The calibration curve was prepared using different concentrations of Gallic acid, ranging from 0 to $50 \mathrm{mg} / \mathrm{L}$. In this study, an equation of $\mathrm{Y}=0.0011 \mathrm{X}$ was obtained, where $\mathrm{Y}$ represents absorbance and $\mathrm{X}$ represents Gallic acid concentration $(\mathrm{mg} / \mathrm{L})$. TPC was expressed as milligrams of Gallic acid equivalents per liter of sample (mg GAE/L).

\section{RESULTS AND DISCUSSION}

\section{Characterization of palm oil mill sterilization condensate}

Characterization to determine the total phenolic compound (TPC) in the palm oil sterilization steam condensate shows that $2627.3 \mathrm{mg}$ GAE/L of TPC was obtained. TPC in the sample obtained from palm oil sterilization steam condensate are possibly water-soluble polyphenols. According to the literature, POME contains approximately $2778.11 \mathrm{mg}$ GAE/L [13]. Hence, TPC obtained in this experiment suggests that most of TPC in POME (around $94 \%$ ) can be found in the palm oil sterilization steam condensate. This is evidence that steam used in the sterilization process have possibly caused the palm phenolics in fresh fruit bunches (FFB) to be washed away, thus ending up in the sterilization steam condensate. Meanwhile, $\mathrm{pH}$ of the condensate was found to be 5. According to Manna et al. [14], this is a favorable condition for polyphenols extraction, which is in the range of pH 4-6.

\section{Emulsion liquid membrane formulation}

\section{Diluent selection}

Diluents play an important role in the ELM process. In order to incorporate a green ELM system, which is more nature-friendly and non-toxic, the commonly used petroleum-based diluents are attempted to be replaced by using renewable and non-toxic diluents. Hence, three types of diluent, consisting of green vegetable-based diluent and conventional petroleum-based diluent were screened in this study. The results obtained are as shown in Fig. 2.

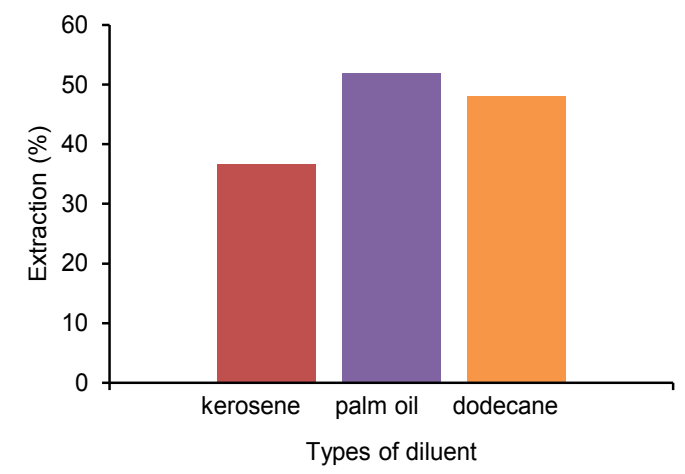

Fig. 2 Percentage of polyphenols extraction from diluent screening ([feed]: $262.73 \mathrm{mg}$ GAE/L; carrier: TBP, 1M; agitation speed: 320 rpm; extraction time: 18 hours).

The highest polyphenols was extracted using palm oil (52\%), followed by dodecane (48\%), and kerosene (37\%). Palm oil (83.2 $\mathrm{mPa} . \mathrm{s})$ has higher viscosity than kerosene $(2.2 \mathrm{mPa} . \mathrm{s})$ and dodecane (1.36 mPa.s) [14]. Dodecane performed better extraction than kerosene due to its lower viscosity compared to kerosene, which creates a lower resistance in mass transport. This result is in agreement with other studies which have mentioned that diluents are desired to be of low viscosity in order to achieve higher extraction performances $[15,16]$.

Despite having a higher viscosity which may increase resistance to mass transport, palm oil shows higher extraction than the two petroleum-based diluents with lower viscosity. This is because palm oil can act as a co-carrier for the transportation of polyphenols. Palm oil contains triglycerides, which can react with polyphenols by forming hydrogen bonding or intermolecular interactions between them. Meanwhile, dodecane and kerosene contain mainly aliphatic hydrocarbon structure and could not form any chemical reaction with polyphenols. This finding is consistent with Othman et al. [16] who reported palm oil has the ability to dissolve phenolic substances. Rosly et al. [17] also indicate that the transportation of solute is better using palm oil compared to aliphatic hydrocarbons. Hence, palm oil that possess a non-polar nature and triglycerides acts as a good diluent as well as co-carrier for TBP.

\section{Carrier selection}

Since this study incorporates Type II ELM process, carrier selection is conducted via solvent extraction. Three types of extractants were screened in terms of their capability on extracting polyphenols compounds from palm oil sterilization steam condensate. The effect of carrier types is as shown in Fig. 3.

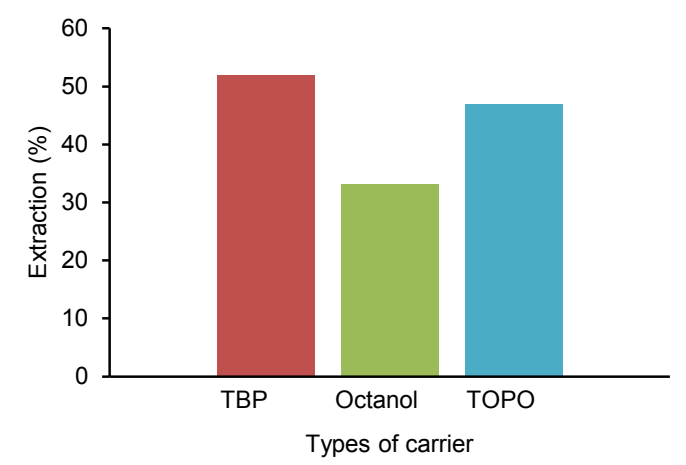

Fig. 3 Percentage of polyphenols extraction from carrier screening ([feed]: $262.73 \mathrm{mg}$ GAE/L; diluent: palm Oil; [carriers]: 1M; agitation speed: 320 rpm; extraction time: 18 hours).

The result depicts that the highest polyphenols extraction was achieved by using TBP, which is $52 \%$, followed by TOPO (47\%) and n-Octanol (33\%). TBP is the most efficient extractant as it has the highest extraction percentage. This is possibly due to TBP being able to react with the electron acceptor part of polyphenols, thus providing good selectivity for efficient extraction. This outcome is in accordance to a study by Yim et al. [18].

TOPO and n-Octanol have lower extraction rates than TBP. This is possibly due to these carriers having lower selectivity towards polyphenols, hence the efficiency in extracting polyphenols is lower. TOPO has better selectivity towards polyphenols as compared to nOctanol, which is why TOPO shows better extraction result in contrary to n-Octanol. This finding is consistent with the study by Rahman et al. [19] which shows neutral extractant TOPO having a higher extraction capability as compared to n-Octanol.

\section{Effect of synergized carrier}

Synergism occurs on the basis of combination of carriers to increase the possibilities of bonding of solute to the carrier, thus enabling a more efficient solute transfer process followed by a higher extraction percentage. In this study of synergized carriers, combination of neutral extractants have been conducted in a binary extractant system and the results are as shown in Fig. 4.

The highest polyphenols extraction was by using TBP-n-Octanol synergist (49\%), followed by TOPO-n-Octanol synergist (45\%) and TBO-TOPO synergist (41\%). TBP and n-Octanol shows slightly higher synergistic performance compared to TBP and TOPO or nOctanol and TOPO. The extraction of polyphenols using mixture $\mathrm{n}$ Octanol-TBP compared to single n-Octanol carrier has improved from 
$33 \%$ to $49 \%$. Synergism of n-Octanol-TOPO compared to single nOctanol has shown increment from $33 \%$ to $45 \%$, respectively. This shows that using synergism for n-Octanol increases the extraction percentage due to the possibilities of bonding to occur with polyphenols. This finding is in line with Sarkar et al. [20] whereby synergism enables cooperation or alteration to the molecules.

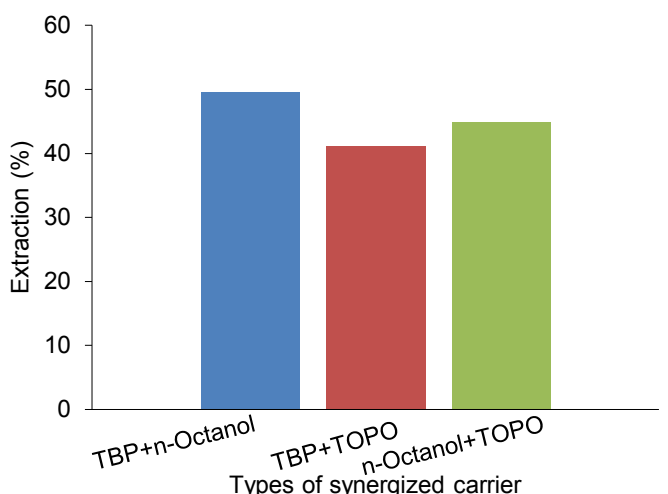

Fig. 4 Percentage of polyphenols extracted from synergized carrier screening ([feed]: $262.73 \mathrm{mg} \mathrm{GAE/L;} \mathrm{diluent:} \mathrm{palm} \mathrm{oil;} \mathrm{[carriers]:} 1 \mathrm{M}$; carrier composition: $1: 1$ by volume; agitation speed: $320 \mathrm{rpm}$; extraction time: 18 hours).

As compared to single TOPO, synergized TOPO with TBP and nOctanol do not show improvement and the same can be observed for single TBP extractant as compared to synergized TBP extractants with TBP and TOPO, respectively. Synergism may not be able to be observed due to certain factors. In this case of synergized TOPO and synergized TBP, the distribution ratio of the binary extractant system has possibly been lower than that of the single carrier system. This finding is as pointed out by previous studies, whereby the carrier synergism is established only when the distribution ratio of the carrier mixture system is greater than the single carrier system whereas the opposite effect occurs if the situation was reversed [21]. Therefore, an overall desired synergistic reaction was unable to be observed with the given composition rate or ratio of extractants used in this screening process. This carrier screening experiment result was based on extraction composition with a ratio of $1: 1$. Hence, the synergized extractant with highest percentage polyphenols extraction, TBP and nOctanol, was chosen to be synergized under different compositions in order to study its effect.

\section{Effect of synergist carrier composition}

Synergistic carriers can be synergized under varying compositions in order to obtain a more desirable or higher percentage of solute extraction. Compositions or ratio of two extractants in the binary extractant system are significant in enabling maximum synergy of two extractants [20]. In this experiment, TBP and n-Octanol have been assorted under different compositions. The results can be viewed in Table 1.

The trend shows that TBP-n-Octanol composition has an increment in extraction percentage from TBP-n-Octanol ratio of 10:0 to TBP-nOctanol $8: 2$ by $52.0 \%$ to $56.4 \%$, respectively. This indicates the cooperation of synergized carriers in efficiently extracting more polyphenols. When more n-Octanol was added into the composition or when the ratio of n-Octanol was increased and that of TBP was decreased, the extraction percentage has shown a reduction from 56.4 $\%$ to $49.8 \%$. The trend becomes relatively plateau with more addition of n-Octanol and starts to decline notably when more than $80 \%$ of the synergized composition of TBP-n-Octanol was dominated by nOctanol.

The trend of result obtained suggests that TBP-n-Octanol of 8:2 has the best distribution ratio as n-Octanol occupies the empty or available sites for bonding of TBP, thus enabling larger mass transfer of polyphenols solutes. However, at a certain limit, in this case at the composition of synergized TBP-n-Octanol of $6: 4$, no more sites are available for bonding and n-Octanol may tend to bond among themselves. This leads to the decline in extraction of polyphenols. The behavior described is known as antagonism that occurs due to a combination of some reagents in certain composition, that causes a decrease in extraction performance.

Table 1 Percentage of polyphenols extraction from varying volume compositions of synergized carrier screening ([feed]: $262.73 \mathrm{mg} \mathrm{GAE/L}$ diluent: palm oil; [Carriers]: $1 \mathrm{M}$; agitation speed $320 \mathrm{rpm}$; extraction time: 18 hours).

\begin{tabular}{cc}
\hline $\begin{array}{c}\text { Synergized composition } \\
\text { (TBP: n-Octanol) by volume }\end{array}$ & Extraction (\%) \\
\hline $10: 0$ & 52.0 \\
$8: 2$ & 56.4 \\
$6: 4$ & 49.8 \\
$5: 5$ & 49.5 \\
$4: 6$ & 48.8 \\
$2: 8$ & 44.6 \\
$0: 10$ & 33.2 \\
\hline
\end{tabular}

\section{Stripping agent selection}

The function of a stripping agent is to re-extract the solute from the organic phase specifically from the stripping-organic interface of the ELM system. In this experimental study, two types of potential stripping agents for the extraction of polyphenols have been screened. The effect of stripping agent types in component selection is as depicted in Fig. 5.

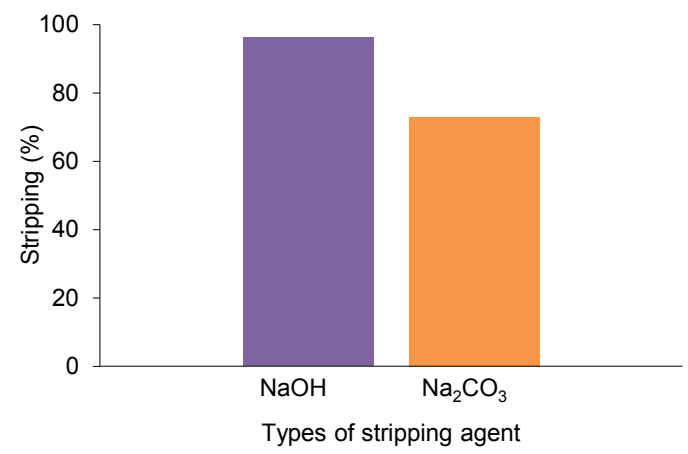

Fig. 5 Percentage of polyphenols stripped from stripping agent screening (Carrier: $1 \mathrm{M}$ TBP and $1 \mathrm{M}$ n-Octanol ( $8: 2$ by volume); [stripping agent]: 1M; agitation speed: 320 rpm, stripping time: 18 hours).

From the result, the highest polyphenols stripping was by using sodium hydroxide $(\mathrm{NaOH}, 96.3 \%)$, followed by sodium bicarbonate $\left(\mathrm{Na}_{2} \mathrm{CO}_{3}, 73 \%\right)$. Since polyphenols is naturally acidic, the $\mathrm{pH}$ difference between the receiving phase and organic phase will serve as the driving force for this stripping process. This is due to the basic stripping agent solutions such as that of $\mathrm{NaOH}$ or $\mathrm{Na}_{2} \mathrm{CO}_{3}$ would dissociate in water to form a strong base which provided a high $\mathrm{pH}$ difference for efficient stripping. $\mathrm{NaOH}$ shows better extraction performance than $\mathrm{Na}_{2} \mathrm{CO}_{3}$ despite both being strong bases. Since the trend of basicity is as follows: $\mathrm{Na}_{2} \mathrm{CO}_{3}<\mathrm{NaOH}$, the strongest base $(\mathrm{NaOH})$ is able to create higher chemical potential among the organic and aqueous stripping phase. This is in line with a study by Rahman et al. [22] where stripping performance increases proportionally with the basicity of stripping agents.

\section{ELM extraction and recovery}

The ELM performance of polyphenols extraction and recovery is as shown in Table 2. This result indicates that high extraction of polyphenols was achieved $(96.5 \%)$. This result can be attributed mainly to the high selectivity of polyphenols that was achieved through the ELM system. This finding is similar to previous studies which have attributed high extraction performance due extraction and stripping steps that take place simultaneously as well as for high selectivity of solute [23-25]. 
Table 2 ELM Performance of polyphenols extraction and recovery ([feed]: $262.73 \mathrm{mg} \mathrm{GAE/L;} \mathrm{treat} \mathrm{ratio} \mathrm{is} \mathrm{1:5;} \mathrm{Span} \mathrm{80:} 1.5 \% \mathrm{w} / \mathrm{v}$; diluent: palm oil; synergized carrier: $1 \mathrm{M}$ TBP and $1 \mathrm{M}$-Octanol (8:2 by volume); stripping agent: $\mathrm{NaOH}(1 \mathrm{M})$; agitation speed: $300 \mathrm{rpm})$.

\begin{tabular}{lc}
\hline Initial external concentration (mg GAE/L) & 262.73 \\
Final external concentration (mg GAE/L) & 9.1 \\
Extraction (\%) & 96.5 \\
Internal concentration (mg GAE/L) & 813.64 \\
Recovery (\%) & 31 \\
Enrichment & 3.1 \\
\hline
\end{tabular}

A few comparisons of the high extraction of polyphenols achieved by ELM in contrast to other techniques are presented in Table 3. As compared to previous studies done in the extraction of palm phenolics, it shows that application of other techniques such as combination of extraction techniques consumes time, expensive equipment and meticulous use of equipment to achieve a high extraction rate as obtained in this experiment [26]. Moreover, studies show that commonly used solvent extraction techniques in polyphenols extraction from tea leaves have relatively low extraction performance [27] Meanwhile, a comparatively high extraction was obtained from a study of polyphenols extraction from simulated Gallic acid solution using solvent extraction and ELM. It was also reported that a lower volume of organic solution with lower carrier concentration is required in ELM compared to solvent extraction [18]. Therefore, this result suggests that using ELM, a cost-efficient method with minimal use of chemicals is able to result in high extraction performance.

Table 3 Comparison of polyphenols extraction and recovery performance using different methods.

\begin{tabular}{|c|c|c|c|c|}
\hline $\begin{array}{l}\text { Extraction } \\
\text { method }\end{array}$ & $\begin{array}{c}\text { Extraction } \\
(\%)\end{array}$ & $\begin{array}{c}\text { Recovery } \\
(\%)\end{array}$ & Enrichment & Reference \\
\hline $\begin{array}{l}\text { ELM (real } \\
\text { waste) }\end{array}$ & 96.5 & 31 & 3.1 & This study \\
\hline MAE & 22 & $\mathrm{~N} / \mathrm{A}$ & $N / A$ & [26] \\
\hline $\begin{array}{l}\text { Solvent } \\
\text { extraction }\end{array}$ & 19.33 & $\mathrm{~N} / \mathrm{A}$ & $\mathrm{N} / \mathrm{A}$ & [27] \\
\hline $\begin{array}{l}\text { Solvent } \\
\text { extraction }\end{array}$ & 75 & 75 & 1 & [18] \\
\hline $\begin{array}{l}\text { ELM (Gallic } \\
\text { acid) }\end{array}$ & 92 & $\mathrm{~N} / \mathrm{A}$ & 12 & [18] \\
\hline
\end{tabular}

However, the recovery of polyphenols is relatively low which is only $31 \%$. The most contributing factor that is suspected to cause a low recovery is the effect of initial feed concentration. The percentage of polyphenols recovered or stripped into the internal phase may have been affected due to the external feed phase having too high concentration $\left(\mathrm{C}_{\text {initial }}\right)$, causing the internal stripping phase $\left(\mathrm{C}_{\text {internal }}\right)$ to be easily saturated, hence contributing to a low recovery. This may have also been possible as the feed phase as characterized, has high amounts of polyphenols and the conditions of ELM was possibly not optimal for recovery. Similar conditions have been mentioned by Venkatesan and Meera Sheriffa Begum [28] and Jusoh et al. [29] where increasing the concentration of external feed phase leads to an increment in stripping, however, at a certain point, internal phase will be saturated due the increased feed concentration, causing percentage of solute stripped to decrease.

Extraction time or emulsifying time may influence the performance of stripping and recovery. The extraction time allocated for the ELM system in this study, which is the time spent in the agitator was approximately 3 minutes. Extraction time refers to the moment the feed phase is mixed with the external feed phase using an agitator. The time may not have been sufficient to strip polyphenols. Othman et al. [30] acknowledged that 3 minutes was inadequate for high extraction to be achieved, but not for high recovery performance due to swelling effect. Another study by Kargari et al. [31] can also comply with this finding whereby the time for extraction will increase when the external phase concentration is high. Hence, in this ELM study, the time intended to strip polyphenols into the internal aqueous phase may not have been adequate.

Since polyphenols or palm phenolics have not been extracted by emulsion liquid membranes prior to this work and no similar studies have been published, the cause of low recovery is difficult to pinpoint. However, from other emulsion studies, a common indication for low recovery can be due to $\mathrm{W} / \mathrm{O}$ instability. This can be supported by studies by who has shown that despite having a high extraction rate, low recovery may occur due instability [32]. Several factors affecting ELM stability should be considered such as $\mathrm{pH}$ of the feed phase, homogenizer speed, surfactant concentration, and organic to internal ratio [33].

On the other hand, the enrichment of recovered polyphenols (3.1 times compared to initial concentration) is higher compared to other extraction method. However, the enrichment is not as good as obtained by other ELM process. The enrichment reported in literature can be as high as 10 to $20[34,35]$. The low enrichment is particularly related to the low recovery obtained in this study. In order to extend the application of ELM for polyphenols recovery, some improvements are necessary, such as the investigation of other process parameters affecting the ELM system.

\section{CONCLUSION}

The feasibility of using emulsion liquid membrane (ELM) to extract and recover polyphenols from palm oil sterilization steam condensate was investigated. It can be concluded that palm oil sterilization steam condensate can be regarded as a good source of polyphenols (2627.3 $\mathrm{mg}$ GAE/L of polyphenols was found in the sample). Also, palm oil as a diluent, synergized carriers TBP-n-Octanol ( $1 \mathrm{M}$, ratio $8: 2$ by volume), and $\mathrm{NaOH}$ as a stripping agent were selected as the ELM formulation for this study. Lastly, using formulated components as stated and emulsion conditions of 1:5 treat ratio, 300 rpm rotational speed with 3 minutes agitation time, extraction of 96.5 $\%$, recovery of $31 \%$, and 3.1 times enrichment was obtained.

\section{ACKNOWLEDGEMENT}

The authors would like to acknowledge the Ministry of Higher Education (MOHE) and Universiti Teknologi Malaysia (PDRU: Q.J130000.21A2.04E65; CRG 40.0: Q.J130000.2451.08G02; CRG 40.2: R.J130000.7351.4B427), and Centre of Lipids Engineering and Applied Research (CLEAR), University Teknologi Malaysia (UTM) for the facilities provided throughout this research.

\section{REFERENCES}

[1] Ahmad, A., Ismail, S., \& Bhatia, S. (2003). Water recycling from palm oil mill effluent (POME) using membrane technology. Desalination, 157(1), $87-95$.

[2] Middleton, E., Jr., Kandaswami, C., \& Theoharides, T. C. (2000). The effects of plant flavonoids on mammalian cells: implications for inflammation, heart disease, and cancer. Pharmacological Reviews, 52(4), 673-751.

[3] Loganathan, R. (2009). Palm oil: Rich in health promoting phytonutrients. Palm oil Development, 50, 16-25.

[4] Lippi, G., Franchini, M., Favaloro, E. J., \& Targher, G. (2010). Moderate red wine consumption and cardiovascular disease risk: Beyond the "French paradox". Semin Thromb Hemost, 36(1), 59-70.

[5] Andriantsitohaina, R., Auger, C., Chataigneau, T., Etienne-Selloum, N., Li, H., Martinez, M. C., Schini-Kerth, V. B., \& Laher, I. (2012). Molecular mechanisms of the cardiovascular protective effects of polyphenols. British Journal of Nutrition, 108(9), 1532-1549.

[6] Abeywardena, M., Sundram, K., Sambanthamurthi, R., \& Tan, Y. A. (2014). Oil palm phenolics as a bioactive ingredient in promoting cardiovascular health. Journal of Oil Palm, Environment \& Health, 5, 3848.

[7] Panja, P. (2017). Green extraction methods of food polyphenols from vegetable materials. Current Opinion in Food Science, 23, 173-182.

[8] Kumar, P. S., Arun Kumar, N., Sivakumar, R., \& Kaushik, C. (2009). Experimentation on solvent extraction of polyphenols from natural waste. Journal of Materials Science, 44(21), 5894-5899. 
[9] Malik, M. A., Hashim, M. A., \& Nabi, F. (2012). Extraction of metal ions by ELM separation technology. Journal of Dispersion Science and Technology, 33(3), 346-356.

[10] Jusoh, N., Othman, N., \& Alina Nasruddin, N. (2016). Emulsion liquid membrane technology in organic acid purification. Malaysian Journal of Analytical Sciences, 20, 436-443.

[11] Abbassian, K., \& Kargari, A. (2016). Modification of membrane formulation for stabilization of emulsion liquid membrane for extraction of phenol from aqueous solutions. Journal of Environmental Chemical Engineering, 4(4, Part A), 3926-3933.

[12] Noah, N. F. M., Jusoh, N., Othman, N., Sulaiman, R. N. R., \& Parker, N. A. M. K. (2018). Development of stable green emulsion liquid membrane process via liquid-liquid extraction to treat real chromium from rinse electroplating wastewater. Journal of Industrial and Engineering Chemistry, 66, 231-241.

[13] Teh, S. S., Hock Ong, A. S., \& Mah, S. H. (2017). Recovery and utilization of palm oil mill effluent source as value-added food products. Journal Oleo Science, 66(11), 1183-1191.

[14] Manna, M. S., Bhatluri, K. K., Saha, P., \& Ghoshal, A. K. (2012). Transportation of catechin $( \pm \mathrm{C})$ using physiologically benign vegetable oil as liquid membrane. Industrial and Engineering Chemistry Research. 51, $15207-15216$

[15] Mohamad, M. (2013). Recovery of Lignin from Liquid Waste Solution Using Emulsion Liquid Membrane (ELM) Process. (Bachelor degree thesis). Universiti Teknologi Malaysia, Malaysia.

[16] Othman, N., Noah, N. F. M., Lim, Y. S., Ooi, Z.Y., Jusoh, N., Idroas, M., \& Goto, M. (2017). Easy removing of phenol from wastewater using vegetable oil-based organic solvent in emulsion liquid membrane process. Chinese Journal of Chemical Engineering, 25(1), 45-52.

[17] Rosly, M. B., Othman, N., \& Rahman, H. A. (2018). Liquid membrane component selection for removal of phenol from simulated aqueous waste solution. Malaysian Journal of Analytical Sciences, 22(4), 702-714.

[18] Yim, K. H., Stambouli, M., \& Pareau, D. (2014). Solvent and emulsion extractions of gallic acid by tributylphosphate: Mechanisms and parametric study. Solvent Extraction and Ion Exchange, 32(7), 749-762.

[19] Rahman, H. A., Othman, N., Rosly, M. B., Sulaiman, R. N. R., Jusoh, N., \& Noah, N. F. M. (2018). Synergistic extraction for extraction of remazol orange $3 \mathrm{R}$ in liquid membrane formulation. Malaysian Journal of Analytical Sciences, 22(4), 626-632.

[20] Sarkar, R., Ray, S., \& Basu, S. (2014). Synergism in solvent extraction and solvent extraction kinetics. Journal of Chemical, Biological and Physical Sciences (JCBPS), 4(4), 3156.

[21] Sulaiman, R. N. R., \& Othman, N. (2018). Solvent extraction of nickel ions from electroless nickel plating wastewater using synergistic green binary mixture of D2EHPA-octanol system. Journal of Environmental Chemical Engineering, 6(2), 1814-1820.

[22] Rahman, H. A., Jusoh, N., Othman, N., Rosly, M. B., Sulaiman, R. N. R. \& Noah, N. F. M. (2019). Green formulation for synthetic dye extraction using synergistic mixture of acid-base extractant. Separation and Purification Technology, 209, 293-300.

[23] Darvishi, D., Haghshenas, D. F., Alamdari, E. K., Sadrnezhaad, S. K., \& Halali, M. (2005). Synergistic effect of Cyanex 272 and Cyanex 302 on separation of cobalt and nickel by D2EHPA. Hydrometallurgy, 77(3), 227238.

[24] Sabry, R., Hafez, A., Khedr, M., \& El-Hassanin, A. (2007). Removal of lead by an emulsion liquid membrane: Part I. Desalination, 212(1-3), 165 175 .

[25] Goyal, R. K., Jayakumar, N., \& Hashim, M. (2011). Chromium removal by emulsion liquid membrane using [BMIM] $+[\mathrm{NTf} 2]-$ as stabilizer and TOMAC as extractant. Desalination, 278(1-3), 50-56.

[26] Saifuddin, N. M., Saltanat, A., \& Hussein, R. (2014). Enhancing the removal of phenolic compounds from palm oil mill effluent by enzymatic pre-treatment and microwave-assisted extraction. Chemical Science Transactions, 3(3), 1083-1093.

[27] Bharadwaz, A., \& Bhattacharjee, C. (2012). Extraction of polyphenols from dried tea leaves. International Journal of Scientific \& Engineering Research, 3(5), 1-5.

[28] Venkatesan, S., \& Meera Sheriffa Begum, K. M. (2009). Emulsion liquid membrane pertraction of imidazole from dilute aqueous solutions by Aliquat-336 mobile carrier. Desalination, 236(1), 65-77.

[29] Jusoh, N., Noah, N. F. M., \& Othman, N. (2018). Extraction and recovery optimization of succinic acid using green emulsion liquid membrane containing palm oil as the diluent. Environmental Progress \& Sustainable Energy, 38(3), 1-9.

[30] Othman, N. (2016). Emulsion liquid membrane for wastewater treatment. In E. Drioli \& L. Giorno (Eds.), Encyclopedia of Membranes (pp. 684 686). Berlin, Heidelberg: Springer Berlin Heidelberg.

[31] Kargari, A., Kaghazchi, T., Sohrabi, M., \& Soleimani, M. (2004). Batch extraction of gold (III) ions from aqueous solutions using emulsion liquid membrane via facilitated carrier transport. Journal of Membrane Science, 233(1), 1-10.

[32] Sulaiman, R., Othman, N., \& Amin, N. (2013). Recovery of ionized nanosilver from wash water solution using emulsion liquid membrane process. Jurnal Teknologi (Sciences and Engineering), 65(4), 33-36.

[33] Jusoh, N., Noah, N. F. M., \& Othman, N. (2018). Double emulsion (waterin-oil-in-water) system in succinic acid extraction - A stability study. Chemical Engineering Transactions, 63, 523-528.

[34] Othman, N., Sulaiman, R. N. R., Rahman, H. A., Noah, N. F. M., Jusoh, N., \& Idroas, M. (2018). Simultaneous extraction and enrichment of reactive dye using green emulsion liquid membrane system. Environmental Technology, 40(11), 1-9.

[35] Raji, M., Abolghasemi, H., Safdari, J., \& Kargari, A. (2018). Selective extraction of dysprosium from acidic solutions containing dysprosium and neodymium through emulsion liquid membrane by Cyanex 572 as carrier. Journal of Molecular Liquids, 254, 108-119. 